\title{
Almost but not quite human: defining the human species through infrahuman figures
}

\author{
Megan H. Glick: Infrahumanisms: science, culture, and the making of \\ modern non/personhood. Durham and London: Duke University Press, \\ 2018, 288 pp, USD\$25.95 PB
}

\section{Rose Trappes $^{1}$}

(c) Springer Nature B.V. 2019

It is a rare work that can bring together topics as disparate as childhood, nonhuman primates, aliens, xenotransplantation, and AIDS. Megan Glick's Infrahumanisms does just that, sketching a history of the boundaries of humanity in twentieth-century US culture, science, and politics. Drawing on a wide array of sources, the book presents historical and contemporary figures at the human-nonhuman boundary and the intense debates and policing that such figures have incited. Glick argues that the biological and cultural category of the human is implicated in generating inequalities not just between human and nonhuman animals, but also between races, sexes, sexualities, and abilities. Full of surprising connections and intriguing insights, Infrahumanisms is a rich and stimulating contribution to the literature on eugenics, biomedicalization, and biopolitics in general.

The book introduces various figures that have been understood as liminally human - children, nonhuman primates, and aliens-as well as cases that cross the border between human and nonhuman-cross-species diseases, xenotransplantation, and obesity. These figures represent what Glick calls the "infrahuman", a state less than but almost human. Glick adopts the term "infrahuman" from Robert Mearns Yerkes, an early twentieth-century psychologist and primatologist. Yerkes briefly used the term to refer to the "almost human" nature of nonhuman primates, in the belief that they represent a missing evolutionary link and are thus exemplary of primitive human minds. Infrahuman is thus a complicated term, since it distinguishes between the human species and nonhumans while simultaneously establishing a proximity and comparability between the two.

The examples that Glick gives of the infrahuman are illustrative of its status as almost human. Children, for instance, were regarded by some psychologists

Rose Trappes

rtrappes@uni-bielefeld.de

1 Department of Philosophy, Bielefeld University, Bielefeld, Germany 
and evolutionary biologists at the turn of the twentieth century as equivalent to primitive humans. Development was consequently seen as a process of evolution into modern Western adult humans. For example, Glick points out how jungle gyms and Scouts groups were advocated as a way of letting children express their primitive natures and thereby progress through the evolutionary-cum-developmental stages to adulthood. To take another example, Glick discusses how alien sightings in the USA in the 1950s may have been related to anxieties connected to World War II. Glick conjectures that the typical "short grey" alien figure is visually similar to the emaciated Holocaust victims depicted in widely publicized photographs. Hence, she suggests a connection between the dehumanized Holocaust victim, a being that has had its humanity stripped away, and the infrahuman alien, a being that is similar to but not quite human.

Glick argues that considering the infrahuman brings something new to theorizing biopolitics. Terms such as subhuman and inhuman tend to focus on the treatment of humans as either political subjects or objects of power. Giorgio Agamben's "bare life", for instance, is generated when a person is stripped of their status as subject and treated as living matter to be subjected to power. In contrast, Glick's infrahuman concerns the complex and contested species boundary: What is it that makes some living beings members of the human species, and others members of other species? This can sound like a purely biological question to be answered by taxonomists or evolutionary biologists. Nevertheless, Glick insists that species is just as much a social category as a biological one. Like races, sexes, and abilities, species are differentiated in a process that is contingent on social and scientific discourses.

While the infrahuman is certainly focused on the definition of the human as a species, Glick also argues that it is still intimately connected to the definition of the human as an ethical and political subject. For instance, Glick examines Yerkes' proposed differentiation and hierarchy between chimpanzees, bonobos, and gorillas, which was based on and reinforced racial stereotypes. Yerkes believed that chimpanzees possessed greater intelligence as well as features closer to white humans such as straight hair and paler skin. In contrast, gorillas were for Yerkes less intelligent and had black faces and densely curled hair. In defining the proximity of the infrahuman primates to humans, Yerkes also defined racial differences amongst humans, even implying that African people are also something of an infrahuman figure. This crossing of racial and species hierarchies demonstrates the intertwining of social and biological discourses in shaping the definition and evaluation of both species and races.

In a similar vein, Glick considers how racism inflected the debate about how the "bushmeat" trade in Africa may have caused AIDS. Consumption of primate meat was construed as close to cannibalism, shifting nonhuman primates closer to the human boundary while at the same time inciting disgust and outrage at inhumane Africans. Another example is Glick's analysis of the connections between pigs and humans in both xenotransplantation research and obesity. Glick highlights the popular suggestion that humans are degenerating into a pig-like being through modern lifestyles that cause obesity. To this mix, she adds the debate about using pigs to grow organs for implantation into humans. Glick argues that the perceived 
degeneration and crossing over of the human to the pig incites anxieties about the proximity of the infrahuman.

The many cases that Glick considers certainly illustrate the importance of infrahuman figures in the discourse around the human-nonhuman boundary as well as other differences between humans. The polarized opinions and emotions surrounding the infrahuman demonstrate that the human-nonhuman border is a crucial and ever contested limit for ethical, juridical, social, and biomedical thought. This is the core of Glick's work, and she makes her point convincingly. Less persuasive are the arguments that Glick offers for her grander claims about what her analysis means for the definition of humanity.

First, Glick argues that the definition of the human is always exclusionary and generates inequality. A key to justifying this claim is the idea of "infrahumanisms". Infrahumanisms are ideologies and practices concerning the species boundary that reinforce hierarchies between species as well as human hierarchies such as racism and sexism. Glick implies that infrahumanisms are necessarily involved in defining the human. Hence, the definition of humanity is always exclusionary and always creates inequality, and the project for universal humanity is not a liberating one but rather one that reinforces "axes of inequality, violence, and biological essentialism" (9). Like all categories, whether of species or of valuable lives, the human is certainly exclusionary. However, it is not obvious that the definition of humanity necessarily generates hierarchical differences. The hierarchical picture of life might be common in historical cases and present-day popular science. Nevertheless, there are alternative species definitions that reject the idea that some species are "more evolved" and some less so. We should pursue such nonhierarchical definitions of the human before we deny their possibility from the outset.

Second, while Glick's examples show that there is a connection between the definition of the human as a species and the allocation of moral or political value, the nature of this connection is more complicated than Glick suggests. For instance, Glick cites the fact that the ethical treatment of children first came into view under the auspices of animal welfare. Here, ethical value was assigned not by virtue of children belonging to the human species, but rather by virtue of their proximity to animals. Thus, it is not apparent that belonging to the human species and having ethical value always go together, contrary to Glick's presentation. Similarly, Glick suggests that animal welfare advocates implicitly place greater value on the human species since the characteristics used to justify animal rights, such as intellectual or emotional capacities, were previously considered to be restricted to the human species. Yet animal rights advocates are claiming that these capacities are ethically and politically valuable in their own right, regardless of which species possesses them. It is therefore again unconvincing that value always has to accompany membership in the human species. Rather than seamlessly "bridging the gap" between the human as a species and the human as a bearer of rights and ethical value, the infrahuman seems to bring to light the extremely complicated and deeply troubled relation between the human and the infrahuman, showing both where they coincide and where they come apart.

This is in the end the true achievement of Glick's work. In developing and applying the concept of the infrahuman, Glick has brought into view the important and 
complex relation between defining humans as a species and determining the limits of ethical concern and political subjectivity. The survey of various historical moments in which the infrahuman has arisen offers ample material to elaborate this relation in greater detail. A more detailed comparison of the infrahuman with the subhuman and inhuman would also be worthwhile to determine how they relate to one another and how thinking about species can change analyses based on these more standard biopolitical categories. In addition, it would be important to determine whether and how the concept of the infrahuman extends beyond the USA to other geographical, cultural, political, and historical contexts. One book cannot do everything, but Glick has succeeded in establishing the boundary work of the infrahuman in constructing and policing the human-nonhuman boundary, as well as shaping human differences like race, sex, ability, and sexuality.

Publisher's Note Springer Nature remains neutral with regard to jurisdictional claims in published maps and institutional affiliations. 